\title{
Helicobacter pylori vacA gene detection in saliva of patients with upper gastrointestinal disorders in Accra, Ghana
}

\author{
Richard H. Asmah ${ }^{1,}$, Timothy Archampong ${ }^{2}$, Charles A. Brown ${ }^{1}$, Samuel B. Ntiamoah ${ }^{1}$, \\ Ebenezer K. Aidoo ${ }^{3}$, Richard Gyasi ${ }^{4}$, Edwin K. Wiredu ${ }^{1}$ \\ ${ }^{1}$ Dept. of Medical Laboratory Sciences, University of Ghana School of Allied Health Science, Accra, Ghana \\ ${ }^{2}$ Dept. of Medicine, University of Ghana Medical School, Accra, Ghana \\ ${ }^{3}$ Dept. of Microbiology, University of Ghana Medical School, Accra, Ghana \\ ${ }^{4}$ Dept. of Pathology, University of Ghana Medical School, Accra, Ghana
}

Email address:

rhasmah@chs.edu.gh (R. H. Asmah)

\section{To cite this article:}

Richard H. Asmah, Timothy Archampong, Charles A. Brown, Samuel B. Ntiamoah, Ebenezer K. Aidoo, Richard Gyasi, Edwin K. Wiredu. Helicobacter Pylori vacA Gene Detection in Saliva of Patients with Upper Gastrointestinal Disorders in Accra, Ghana. International Journal of Genetics and Genomics. Vol. 2, No. 5, 2014, pp. 80-83. doi: 10.11648/j.ijgg.20140205.11

\begin{abstract}
Helicobacter pylori play an essential role in the pathogenesis of upper gastrointestinal disorders. The diagnostic role of the bacterium thus has been a subject of intense investigations. In this study we used an immune-chromatographic method and the polymerase chain reaction (PCR) to detect H. pylori in the saliva of patients with clinically diagnosed upper gastrointestinal disorders. Thirty such patients reporting to the Korle-Bu Teaching Hospital (Accra, Ghana) for upper gastrointestinal endoscopy consented for this study. Saliva samples were collected from each subject and analysed for $H$. pylori antibodies using a rapid immuno-chromatographic assay and H. pylori DNA by nested PCR using specific primers. Ten (33.3\%) out of the 30 samples tested positive for the saliva antibody test with the most prevalent gastrointestinal disorders among the positive subjects being peptic ulcer $(60 \%)$ followed by gastritis (30\%) and esophagitis (10\%). Following nested PCR analysis, a 346bp fragment of the vacA $(\mathrm{m} 2)$ gene region of $H$. pylori was amplified in $9(90 \%)$ out the 10 samples that were positive by the rapid immuno-chromatographic assay. Saliva samples could serve as a reliable non-invasive alternative to detect the presence of $H$. pylori infection in synergy with available diagnostic methods in Ghana.
\end{abstract}

Keywords: Helicobacter Pylori, Saliva, Polymerase Chain Reaction

\section{Introduction}

Helicobacter pylori bacteria are responsible for most upper gastrointestinal diseases. The bacterium causes gastritis, peptic ulcers, and over time, gastric cancer [1]. Over $80 \%$ of individuals infected with $H$. pylori are asymptomatic [2]. It is estimated that $H$. pylori-positive patients have a 10 to $20 \%$ lifetime risk of developing ulcer disease and a 1 to $2 \%$ risk of developing distal gastric cancer [3]. In developing countries $H$. pylori contribute to diarrhea, malnutrition and growth failure in young children. Extra gastric disorders such as coronary heart disease, iron deficiency anemia, dermatological disorders, autoimmune thyroid disease and thrombocytopenic purpura, have all been associated with $H$. pylori [4], [5].

Diagnostic tests available for $H$. pylori detection consist of invasive and non-invasive procedures with their respective advantages and disadvantages. The invasive test is based on gastric specimens from endoscopy for histology, culture, urease test or other methods. The non-invasive tests are based on peripheral samples such as blood, breath samples, stools, urine, or saliva for detection of antibodies, bacterial antigens, or urease activity [6],[7]. Though direct diagnosis of $H$. pylori via endoscopy is considered a gold standard method a major problem associated with this diagnostic method is inherent in the invasiveness of the procedure. The cost of endoscopy is also high in developing countries [8],[9].

Studies have shown that $H$. pylori DNA and antibodies could both be detected in saliva of infected patients using an immuno-chromatographic method and PCR [10],[11],[12]. Diagnostic procedures that avoid the use of endoscopy would therefore be beneficial to patients and researchers. With collective effort over the years, salivary 
diagnostics have exhibited tremendous potential in clinical applications. This is because saliva has been demonstrated to be a promising body fluid for easy detection of diseases [13]. The salivary diagnostic method largely diminishes discomfort associated with endoscopy and predominant issues related to blood, stool and urine collection. The method avoids the need for blood or biopsy samples in epidemiological studies where large-scale H. pylori's screening is required. Unlike other diagnostic procedures, PCR does not only detect the bacterium present but also detects specific genes relevant to pathogenesis and mutations associated with antimicrobial resistance [14]. Further studies directed towards understanding of this diagnostic procedure would be beneficial to $H$. pylori diagnosis and its related epidemiological research.

In this study we used nested PCR analysis and immuno-chromatographic dip stick to detect $H$. pylori in saliva of patients with clinically diagnosed upper gastrointestinal disorders.

\section{Materials and Methods}

\subsection{Study Subjects}

Patients clinically diagnosed with upper gastrointestinal disorders and who reported to the Korle-Bu Teaching Hospital (KBTH) for upper gastrointestinal endoscopy were recruited.

\subsection{Ethical Issues}

Ethical clearance was obtained from the Ethics and Protocol Review Committee of the School of Allied Health Sciences, College of Health Sciences, University of Ghana. Appropriate approval was also obtained from the Medical Directorate of KBTH. All patients gave their consent.

\subsection{Saliva Sample Collection}

The protocol for saliva collection and processing was derived from the "Salivary Proteome Handbook Procedures and Protocols" [15]. Saliva collection was done prior to endoscopy after subjects' demographic data consisting of age, sex and clinical diagnosis was taken. Each of the subjects was given a $10 \mathrm{ml}$ sterile Falcon tube with the pathological number correctly assigned to it.

Subjects were then given drinking water and asked to rinse their mouth out well without drinking the water. They were asked to refrain from talking and to bow their heads to let the saliva run naturally to the front of the mouth. Subjects were alerted not to cough up mucus as saliva is collected and not sputum. They were asked to spit whole saliva into the given sterile Falcon tubes. Collected samples were kept on ice at all times prior to processing. Saliva samples were then taken to the laboratory for investigation.

\subsection{Saliva Antibody Test}

A commercial kit (HiSens H. Pylori antigenic cassette, HBI Co. Ltd., Korea), a rapid immuno-chromatographic assay was used for the qualitative detection of saliva antibodies to $H$. Pylori. All specimens and test devices were brought to room temperature $\left(25^{\circ} \mathrm{C}\right)$ for $15-30$ minutes before testing as recommended by the manufacturer.

\subsection{Genomic DNA Extraction}

Genomic DNA was extracted from the stored saliva samples using the QIAGEN DNA Mini Kit (QIAGEN Co. Ltd, USA) following the manufacturer's instruction. The extracted genomic DNA was stored at $-20^{\circ} \mathrm{C}$ until required for use.

\subsection{Nested PCR Analysis}

The Helicobacter genome vacA signal sequence and middle regions of the DNA were analyzed by PCR as previously described [16] with some modifications. The sequence details of the primers are given in Table 1. Each DNA amplification reaction was carried out in a final volume of $25 \mu \mathrm{l}$ and consisted of $1 \mathrm{X}$ PCR buffer plus $\mathrm{MgCl}_{2}$ (OneTaq ${ }^{\circledR}$ Standard Reaction Buffer Pack, New England Biolabs, MA, USA), 1U of Taq polymerase, $200 \mu \mathrm{M}$ of each dNTP and 500nM of each primer.

The first amplification reaction used $10 \mu$ of the extracted DNA as the template for each PCR whilst the second amplification was accomplished by using $1 \mu \mathrm{l}$ of the first product as the DNA template for each PCR. Each PCR reaction mix was thoroughly mixed before the amplification. The PCR reaction profile used in both the first and second amplifications involved an initial denaturation at $95^{\circ} \mathrm{C}$ for 3 min followed by 35 cycles of denaturation at $95^{\circ} \mathrm{C}$ for $50 \mathrm{~s}$, annealing for $1 \mathrm{~min}$ at $55^{\circ} \mathrm{C}$ for vac1F-vac1R and $60^{\circ} \mathrm{C}$ for vac3F-vac3R and vac $4 \mathrm{~F}-\mathrm{vac} 4 \mathrm{R}$, extension at $72^{\circ} \mathrm{C}$ for $1 \mathrm{~min}$, and a final extension at $72^{\circ} \mathrm{C}$ for $2 \mathrm{~min}$.

The amplification products were analysed by gel electrophoresis in $2 \%$ agarose gels stained with $0.5 \mu \mathrm{g} / \mathrm{ml}$ ethidium bromide. Ten microliters of each sample was added to $2 \mu$ l of orange $\mathrm{G}(5 \mathrm{X})$ gel loading dye for the electrophoresis A hundred base pair DNA molecular weight marker (Sigma, MO, USA) was run alongside the PCR products. The gel was prepared and electrophoresed in 1X TAE buffer using a mini gel system at 100 volts for one hour and the gel photographed over a UV trans-illuminator.

\section{Results}

\subsection{Demographic Data}

A total of thirty (30) patients involving fifteen (15) males and fifteen (15) females who were reporting for upper gastrointestinal endoscopy at KBTH consented for this study. Their ages ranged from five to 90 years. The mean age for males was $44.07 \pm 0.05$ years whilst that of females was 45.80 \pm 0.02 years. The $40-49$ age group had the highest number of patients (Table 2). 
Table 1. Oligonucleotide primer sequences used in amplification [16]

\begin{tabular}{|c|c|c|c|c|}
\hline Gene & Region amplified & Primer designation & Primer sequence & PCR product size (location) \\
\hline \multirow[t]{8}{*}{$\operatorname{vacA}$} & $\mathrm{s} 1^{\mathrm{a}}$ & vac1F & 5'GAAATACAACAAACACACCGC3' & $201(800-1000)^{\mathrm{b}}$ \\
\hline & & $\operatorname{vac} 1 \mathrm{R}$ & 5’GGCTTGTTTGAGCCCCCAG3' & \\
\hline & $\mathrm{s} 2^{\mathrm{a}}$ & $\operatorname{vac} 1 \mathrm{~F}$ & 5'GAAATACAACAAACACACCGC3' & $228(349-576)^{c}$ \\
\hline & & $\operatorname{vac} 1 \mathrm{R}$ & 5’GGCTTGTTTGAGCCCCCAG3’' & \\
\hline & $\mathrm{m} 1$ & Vac3F & 5'GGTCAAAATGCGGTCATGG3' & $388(2741-3128)^{b}$ \\
\hline & & Vac3R & 5’CATCAGTATTTCGCACCACA3' & \\
\hline & $\mathrm{m} 2$ & Vac4F & 5'CCAGGAAACATTGCCGGCAAA3' & $346(2290-2635)^{\mathrm{c}}$ \\
\hline & & Vac4R & 5'CATAACTAGCGCCTTGCA3' & \\
\hline
\end{tabular}

${ }^{a} \mathrm{PCR}$ products of regions $\mathrm{s} 1$ and $\mathrm{s} 2$ were differentiated on the basis of molecular size and restriction endonuclease digestion with NlaIII . ${ }^{b}$ Location in published vacA sequence of strain 60190 (8). 'Location in strain Tx30a (GenBank accession no. U29401).

The commonest reasons underlying the request for upper gastrointestinal endoscopy among subjects included dyspepsia $(20 \%)$, epigastric pain $(10 \%)$, dysphagia $(25 \%)$, and hematemesis and melena $(45 \%)$.

\subsection{Saliva Antibody Test}

In this study, $10(33.3 \%)$ out of the 30 patient samples tested positive for the saliva antibody test (Table 2). The most prevalent gastrointestinal disorder among the positives was peptic ulcer $(n=6)$, followed by gastritis $(n=3)$, then esophagitis $(n=1)$.

\subsection{Nested PCR Analysis}

With the nested PCR analysis, only the 346 bp DNA fragment of the vacA $(\mathrm{m} 2)$ gene region (Fig. 1) was amplified in $9(90 \%)$ out the 10 samples that were positive by the saliva antibody test.

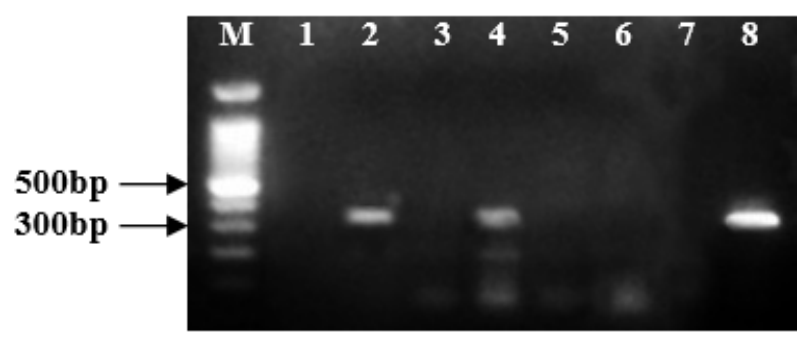

Figure 1. Sample electrophoregram of ethidium bromide stained 2\% agarose gel of PCR products. Lane $M=100 \mathrm{bp}$ marker; Lanes 1,3,5,6 and 7 = PCR negative samples; Lanes 2, 4 and $8=P C R$ positive samples.

Table 2. Distribution of $H$. pylori positive and negative subjects among the various age groups following the salivary antibody test

\begin{tabular}{lll}
\hline Age group & No. of patients & H. pylori positive $(\%)$ \\
\hline $0-9$ & 1 & $1(100)$ \\
$10-19$ & 2 & $1(100)$ \\
$20-29$ & 5 & $1(20)$ \\
$30-39$ & 3 & $2(67)$ \\
$40-49$ & 9 & $2(22)$ \\
$50-59$ & 2 & $0(0)$ \\
$60-69$ & 2 & $1(50)$ \\
$70-79$ & 3 & $1(67)$ \\
$80-89$ & 3 & $1(33)$ \\
Total & 30 & $10(33)$ \\
\hline
\end{tabular}

\section{Discussion}

Helicobacter pylori are recognized as important cause of chronic gastritis, playing a vital pathogenic role in the development of peptic ulcer disease and gastric adenocarcinoma [17]. Polymerase chain reaction protocols have evolved over time in the detection of $H$. pylori in clinical specimens [18]. There is evidence that the mouth may serve as a reservoir for $H$. pylori infection [10].

Studies have shown that $H$. pylori DNA and antibodies could be detected in saliva of infected patients [10],[11],[12]. This is because saliva, a multi constituent oral fluid has been demonstrated to be a promising body fluid for easy detection of diseases [13]. In this work, ten $(33.3 \%)$ out of thirty samples tested positive for $H$. pylori saliva antibody. Nine out of the ten samples were positive by the nested PCR analysis. The results agree with reports from similar studies [8],[12],[11]. According to these studies saliva could serve as a reliable non-invasive alternative for detection of $H$. pylori infection. Conversely, the results disagree with the reports by other researchers [9],[19] that saliva is not a suitable sample for $H$. pylori diagnosis. Other studies have shown variable prevalence of $H$. pylori DNA in patients with proven $H$. pylori infection: 47\% [20] and 30\% [21]. However, another PCR study had a high rate of detection of $H$. pylori DNA in saliva of $75 \%$ of patients with proven gastric $H$. pylori infection [10].

Possible explanations for these differences may be inherent in the variations in either saliva collection or the use of whole saliva samples instead of pellets from saliva for DNA extraction [10]. Methodology may therefore play a part in sensitivity of testing. Peptic ulcer $(60 \%)$ and other upper gastrointestinal disorders like, gastritis (30\%) and esophagitis $(10 \%)$ were observed as the commonest disorders among the $H$. pylori infected subjects. These disorders are known to be associated with $H$. pylori colonization [3],[5].

The results showed no gender bias in the prevalence of the bacteria. Interestingly, the only sample from a 5 year old subject, tested positive in agreement with the hypothesis by Fiedorek et al. [22], Kuiper et al. [23] and Cover et al. [24] that $H$. pylori infection usually occurs at early childhood especially at the age of five. 


\section{Conclusion}

Saliva samples could serve as a reliable non-invasive alternative to detect the presence of $H$. pylori infection in synergy with available diagnostic methods in Ghana.

\section{References}

[1] M.S. Dorer, S. Talarico, N.R Salama, Helicobacter pylori's unconventional role in health and diseases pathology, PLOS Pathogens vol. 5 (10), e1000544, 2009.

[2] E.J. Kuipers, G.I. Pérez-Pérez, S.G. Meuwissen, M.J. Blaser, Helicobacter pylori and atrophic gastritis: importance of the cagA status, J Natl Cancer Inst, vol. 87(23), pp. 1777-1780, 1995.

[3] E.J. Kuipers, Review article: exploring the link between Helicobacter pylori and gastric cancer. Aliment Pharmacol Ther. Suppl 1, pp 3-11, 1999.

[4] G.I. Leontiades, V.K. Sharma, C.W. Howden, Non-gastrointestinal tract associations of Helicobacter pylori infection: what is the evidence? Arch Intern Med, vol. 159, pp. 925-940, 1999.

[5] A. Gasbarrini, F. Franceschi, Does H. pylori infection play a role in idiopathic thrombocytopenic purpura and in other autoimmune diseases? Am J Gastroenterol vol. 100, pp. 1271-1273, 2005.

[6] D. Vaira, P. Malfertheiner, F.A. Megraud, T. Axon, M. Deltenre, G. Hirschl, C. Gasbarrini, J.M. O’Morain-Garcia, M. Quina, G.N. Tytgat, Diagnosis of Helicobacter pylori infection with a new non-invasive antigen-based assay. Lancet, vol. 354, pp. 30-33, 1999

[7] R.M. Zagari, F. Bazzoli, P. Pozzato, S. Fossi, L. De Lucas, G. Nicolini, D. Berretti, E. Roda, Non-invasive methods for the diagnosis of Helicobacter pylori infection. Ital J Gastroenterol, vol. 31, pp. 408-S415, 1999.

[8] S.K. Tiwari, A.A. Khan, K.S. Ahmed, I. Ahmed, F. Kauser, M.A. Hussain, S.M. Ali, A. Alvi, A. Habeeb, Z. Abid, N. Ahmed, C.M Habibullah, Rapid diagnosis of Helicobacter pylori infection in dyspeptic patients using salivary secretion: a non-invasive approach, Singapore Med J, vol. 46 (5), pp. 224-228, 2005.

[9] F. Me'graud, P. Lehours, Helicobacter pylori detection and antimicrobial susceptibility testing, Clin Microbiol Rev, vol. 40, pp. $280-322,2007$

[10] C. Li, P.R Musich, T. Ha, D.A. Ferguson, N.R. Patel, D.S. Chi, E. Thomas, High prevalence of Helicobacter pylori in saliva demonstrated by a novel PCR assay, J Clin Pathol, vol. 48(7), pp. 662-666, 1995

[11] S.I. Mishra, Singh V, Rao GR, Dixit VK, Gulati AK, Nath G, Prevalence of Helicobacter pylori in asymptomatic subjects - a nested PCR based study, Infect Genet Evol, vol. 8(6), pp. 815-819, 2008.

[12] A. El-Mekki, A. Kumar, B. Alknawy, O. Al-Ammari, R. Moosa S. Quli, M. Ahmed, M, Comparison of enzyme immunoassays detecting Helicobacter pylori specific IgG in serum and saliva with endoscopic and biopsy findings in patients with dyspepsia, Indian J Med Microbiol, vol. 29(2), pp. 136-140, 2011.

[13] J.M. Lee, E.V. Garon, D.T. Wong, Salivary diagnostics. Orthod Craniofac Res, vol. 12 (3), pp. 206-211, 1999.

[14] J.G. Kusters, A.H. van Vliet, E.J. Kuipers, Pathogenesis of Helicobacter pylor infection, Clin Microbiol Rev, vol. 19 (3), pp. 449-490, 2006.

[15] National Consortium for the Human Saliva Proteome National Consortium for the human saliva proteome, Salivary Proteome Handbook Procedures and Protocols, 2007.

[16] J. Rudi, C. Kolb, M. Maiwald, D. Kuck, A. Sieg, P.R. Galle, W. Stremmel, Diversity of Helicobacter pylori vac $A$ and cag $A$ genes and relationship to $v a c A$ and $\operatorname{cag} A$ protein expression cytotoxin production and associated diseases, J Clin Microbiol, vol. 36, pp. 944-948, 1998.

[17] D.N. Taylor, M.J. Blaser, The Epidemiology of Helicobacter pylori infection. Epidemiol Rev, vol 13, pp. 42-49, 1991.

[18] J.L. Valentine, R.R. Arthur H.L. Mobley, J.D. Dick, Detection of Helicobacter pylori by using Polymerase Chain Reaction. J Clin Microbiol, vol 29, pp. 689-695, 1991.

[19] J. Parsonnet, H. Shmuely, T. Haggerty, Fecal and oral shedding of Helicobacter pylori from healthy infected adults. J Am Med Assoc, vol. 282, pp. 2240-2245, 1999.

[20] M. Hammer, T. Tyszkeiwicz, T. Wadstrom P.W. O’Toole, Rapid detection of Helicobacter pylori by using the polymerase chain reaction. J Clin Microbiol, vol 30, pp. 54-8, 1992.

[21] N.P. Mapstone, D.A. Lynch, F.A. Lewis. A.T. Axon, D.S Tompkin, M.F. Dison, Identification of Helicobacter pylori DNA in the mouth and stomachs of patients with gastritis using Polymerase Chain Reaction. J Clin Path, 46, pp. 540-3, 1993.

[22] S.C. Fiedorek, H.M Malaty, D.L. Evans, C.L Pumphrey, H.B. Casteel, D.J. Evans, D.Y. Graham, Factors influencing the epidemiology of Helicobacter pylori infection in children, Pediatrics, vol. 88, pp. 578-582, 1991.

[23] E.J. Kuipers, A.M. Uyterlinde, A.S. Pena, H.J Hazenberg, E. Bloemena, J. Lindeman, E.C. Klinkenberg-Knol, S.G. Meuwissen, Increase of Helicobacter pylori-associated corpus gastritis during acid suppressive therapy: implications for long-term safety. Am J Gastroenterol, vol. 90, pp. 1401-1406, 1995.

[24] T.L. Cover, Y. Glupczynski, A.P. Lage, A. Burette, M.K. Tummuru, G.I. Perez-Perez, M.J. Blaser, Serologic detection of infection with cagA, J Clin Microbiol, vol. 33 (2), pp. 1496-500, 1995. 